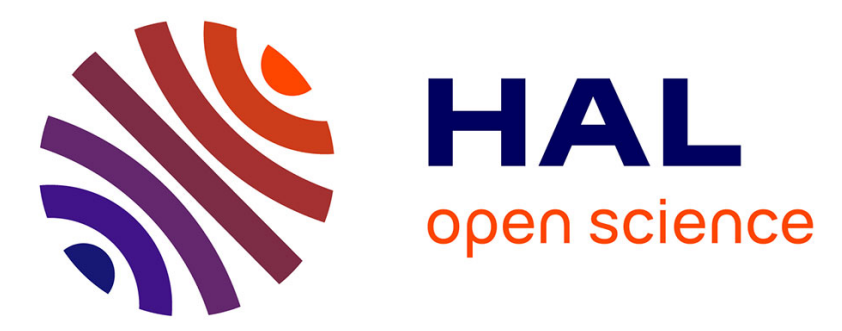

\title{
Measurement of thermal conductance of La0.7Sr0.3MnO3 thin films deposited on SrTiO3 and $\mathrm{MgO}$ substrates
}

\author{
Ammar Aryan, Bruno Guillet, Jean-Marc Routoure, Cédric Fur, Pierre \\ Langlois, Laurence Méchin
}

\section{To cite this version:}

Ammar Aryan, Bruno Guillet, Jean-Marc Routoure, Cédric Fur, Pierre Langlois, et al.. Measurement of thermal conductance of $\mathrm{La} 0.7 \mathrm{Sr} 0.3 \mathrm{MnO} 3$ thin films deposited on $\mathrm{SrTiO} 3$ and $\mathrm{MgO}$ substrates. Applied Surface Science, 2015, 326, pp.204 - 210. 10.1016/j.apsusc.2014.11.119 . hal-01108530

\section{HAL Id: hal-01108530 \\ https://hal.science/hal-01108530}

Submitted on 23 Jan 2015

HAL is a multi-disciplinary open access archive for the deposit and dissemination of scientific research documents, whether they are published or not. The documents may come from teaching and research institutions in France or abroad, or from public or private research centers.
L'archive ouverte pluridisciplinaire HAL, est destinée au dépôt et à la diffusion de documents scientifiques de niveau recherche, publiés ou non, émanant des établissements d'enseignement et de recherche français ou étrangers, des laboratoires publics ou privés.

\section{()ㅜㅇㅜ}

Distributed under a Creative Commons Attribution - NoDerivatives| 4.0 International 


\title{
Measurement of thermal conductance of $\mathrm{La}_{0.7} \mathrm{Sr}_{0.3} \mathrm{MnO}_{3}$ thin films deposited on $\mathrm{SrTiO}_{3}$
} and $\mathrm{MgO}$ substrates

\author{
A. Aryan, B. Guillet, J.M. Routoure, C. Fur, P. Langlois, L. Méchin \\ GREYC (UMR 6072) - CNRS - ENSICAEN - Université de Caen Basse-Normandie \\ 14050 Caen cedex, France
}

\begin{abstract}
We present measurements of the thermal conductance of thin-film-on-substrate structures that could serve as thin film uncooled bolometers. Studied samples were $75 \mathrm{~nm}$ thick epitaxial $\mathrm{La}_{0.7} \mathrm{Sr}_{0.3} \mathrm{MnO}_{3}$ thin films deposited on $\mathrm{SrTiO}_{3}(001)$ and $\mathrm{MgO}(001)$ substrates patterned in square geometries of areas ranging from $50 \mu \mathrm{m} \times 50 \mu \mathrm{m}$ to $200 \mu \mathrm{m} \times 200 \mu \mathrm{m}$. The model allows estimating thermal boundary conductance values at the interface between film and substrate of $0.28 \pm 0.08 \times 10^{6} \mathrm{~W} \cdot \mathrm{K}^{-1} \cdot \mathrm{m}^{-2}$ for LSMO / STO $(001)$ and $5.80 \pm 2.98 \times 10^{6} \mathrm{~W} \cdot \mathrm{K}^{-1} \cdot \mathrm{m}^{-}$ 2 for LSMO / MgO (001) from measurements performed in the static regime. Analytical expressions of thermal conductance and thermal capacitance versus modulation frequency are compared to measurements of the elevation temperature due to absorbed incoming optical power. The overall good agreement found between measurements and model finally provides the possibility to calculate the bolometric response of thin film bolometers, thus predicting their frequency response for various geometries.
\end{abstract}




\section{INTRODUCTION}

A bolometer is a thermal radiation sensor. ${ }^{1,2,3,4}$ It is composed of an absorbing element that converts the incident electromagnetic radiation to heat and an electrical resistance thermometer that measures the elevation of temperature $\Delta \mathrm{T}$ induced by the absorbed radiation. The absorbing element with thermal capacitance $\mathrm{C}$ is connected to a thermal bath at fixed temperature $\mathrm{T}_{0}$ (thermostat or cold head) through a thermal conductance $\mathrm{G}$, which includes the thermal boundary conductance at the interface between film and substrate. This thermal boundary conductance is a quantity used to describe the heat conduction between two materials in contact. It is of high importance to evaluate its value, in case of thin-film-on-substrate systems and in particular of thin film bolometers.

The optical responsivity $\Re_{\mathrm{V}}$ (expressed in $\mathrm{V} \cdot \mathrm{W}^{-1}$ ) of a bolometer of electrical resistance $\mathrm{R}$ is defined as the output voltage $\Delta \mathrm{V}(\mathrm{f})$ per incoming radiation power $\Delta \mathrm{P}(\mathrm{f})$, where $\mathrm{f}$ is the modulation frequency of the incoming radiation power. It is directly related to the elevation of temperature in the bolometer $\Delta \mathrm{T}(\mathrm{f})$ and in the case of a constant current biased bolometer, it can be written as:

$$
\mathfrak{R}_{\mathrm{V}}(\mathrm{f})=\frac{\Delta \mathrm{V}(\mathrm{f})}{\Delta \mathrm{P}(\mathrm{f})}=\frac{\Delta \mathrm{V}(\mathrm{f})}{\Delta \mathrm{T}(\mathrm{f})} \times \frac{\Delta \mathrm{T}(\mathrm{f})}{\Delta \mathrm{P}(\mathrm{f})}=\left(\frac{\mathrm{dR}}{\mathrm{dT}} \times \mathrm{I}\right) \times\left(\frac{\eta}{\mathrm{G} \sqrt{1+(2 \pi \mathrm{f} \tau)^{2}}}\right)
$$

where $\eta$ is the absorption coefficient (dimensionless), $I$ is the bias current (expressed in $A$ ), $G$ is the thermal conductance of the device (expressed in $\mathrm{W} \cdot \mathrm{K}^{-1}$ ), $\tau=\mathrm{C} / \mathrm{G}$ is the thermal time constant (expressed in s), $\mathrm{C}$ is the thermal capacitance (expressed in $\mathrm{J} \cdot \mathrm{K}^{-1}$ ). The basic approach described by equation (1), which considers that $\mathrm{G}$ and $\mathrm{C}$ are constant in all the investigated modulation frequency and temperature range, leads to the conclusion that the bolometer is a first order system with a cut-off frequency equals to $f_{0}=(2 \pi \tau)^{-1}$. However, $G$ and $C$ are not strictly frequency independent in the case of film-on-substrate devices, and this is the purpose of this paper to study their frequency dependence, as well as to evaluate the thermal boundary conductance between the LSMO film and the substrate.

In section II, we will describe the thermal model that we have used for thin-film-onsubstrate bolometers, which is adapted from Ref. 5 and 6. Section III gives the experimental details, i.e. the sample description and the measurement conditions. $\mathrm{La}_{0.7} \mathrm{Sr}_{0.3} \mathrm{MnO}_{3}$ (LSMO) thin films deposited on $\mathrm{SrTiO}_{3}$ (001) (STO) and $\mathrm{MgO}$ (001) substrates patterned in the form of meander-shaped strips that cover square areas of $50 \mu \mathrm{m} \times 50 \mu \mathrm{m}, 100 \mu \mathrm{m} \times 100 \mu \mathrm{m}$, and 200 $\mu \mathrm{m} \times 200 \mu \mathrm{m}$ were studied. LSMO is a promising material for room temperature bolometers 
since it presents a large variation of its electrical resistance versus temperature at the temperature of its metal-to-insulator transition, i.e. above room temperature. ${ }^{7,8,9,10}$ The Temperature Coefficient of the Resistance TCR $=(1 / \mathrm{R}) \times(\mathrm{dR} / \mathrm{dT})$ of $\mathrm{LSMO}$ is around $2 \% \mathrm{~K}^{-1}$ in the $300-340 \mathrm{~K}$ temperature range indeed. ${ }^{7,8}$ In addition, LSMO thin films show low electrical noise, which let expect competitive noise equivalent power at room temperature. ${ }^{9-12}$ The thermal properties of the tested substrate material are given in section IV. Using measurements of the thermal conductance performed in the static regime and the simplified model, thermal boundary conductance values at the interface between film and substrate were evaluated for each substrate material. The temperature elevation versus the modulation frequency of the incoming radiation power from a laser diode, named $\Delta \mathrm{T}(\mathrm{f}) / \Delta \mathrm{P}(\mathrm{f})$ were finally made and compared to the proposed model. A conclusion is given in section $\mathrm{V}$.

\section{THERMAL MODEL}

\section{A. Electro-thermal analogy}

The thermal model is based on heat conduction from film to substrate, neglecting radiative and convective leakage, since samples are placed in vacuum, as well as thermal leakage due to wires. To describe it, we used the conventional analogy between thermal and electrical parameters. ${ }^{13}$ The heat transfer analysis can then be made much simpler by creating an equivalent electrical circuit of the problem as shown in figure 1 , similarly to the one proposed by Bozbey in Ref. 14.

In the model described in figure 1 , we defined $\eta \cdot \Delta \mathrm{P}(\mathrm{f})$ as the absorbed power at the surface of the sample (in $\mathrm{W}$ ), $\mathrm{G}_{\mathrm{F}}$ and $\mathrm{C}_{\mathrm{F}}$ the thermal conductance and the thermal capacitance of the patterned thin film, $\mathrm{G}_{\mathrm{S}}$ and $\mathrm{C}_{\mathrm{S}}$ the thermal conductance and the thermal capacitance of the substrate. Thermal conductances are expressed in $\mathrm{W} \cdot \mathrm{K}^{-1}$ and thermal capacitances in $\mathrm{J} \cdot \mathrm{K}^{-1}$. Two thermal interfaces have to be considered in this description, the film/substrate interface and the substrate/sample holder interface. A. $\mathrm{g}_{\mathrm{FS}}$ is the thermal boundary conductance at the film/substrate interface and $\mathrm{A}^{\prime} \cdot \mathrm{g}_{\mathrm{ST}}$ is the thermal boundary conductance at the substrate/thermostat interface, where $\mathrm{A}$ is the bolometer area and $\mathrm{A}^{\prime}$ is the substrate to thermostat contact area. $\mathrm{g}_{\mathrm{FS}}$ and $\mathrm{g}_{\mathrm{ST}}$ are named the thermal boundary conductances $\left(\mathrm{in} \mathrm{W} \cdot \mathrm{K}^{-}\right.$

${ }^{1} \cdot \mathrm{m}^{-2}$ ) between film and substrate, and between substrate and thermostat, respectively. The total heat flow from film surface to sample holder is governed by the thermal conductance $G$, which can be written as follows in the steady state: 


$$
\frac{1}{G}=\frac{1}{G_{F}}+\frac{1}{A \cdot g_{F S}}+\frac{1}{G_{S}}+\frac{1}{A^{\prime} \cdot g_{S T}}
$$

\section{B. Thermal boundary conductance}

The thermal boundary conductance depends on the surface of the contact area as well as on the interface quality ${ }^{15,16}$. To our knowledge, no value of thermal boundary conductance between LSMO thin films and STO or MgO substrates has been reported in literature so far. Nahum et al. ${ }^{17}$ have performed direct measurements of the thermal boundary conductance between epitaxial $\mathrm{YBa}_{2} \mathrm{Cu}_{3} \mathrm{O}_{7-\delta}(\mathrm{YBCO})$ films and a variety of substrate materials with and without buffer layers in the $0.70 \times 10^{7}-1.25 \times 10^{7} \mathrm{~W} \cdot \mathrm{K}^{-1} \cdot \mathrm{m}^{-2}$ range at temperatures in the 90 $200 \mathrm{~K}$ range. Other measurements at room temperature have been reported for epitaxial YBCO on $\mathrm{MgO}$ substrates $\left(0.4 \times 10^{7}-2.0 \times 10^{7} \mathrm{~W} \cdot \mathrm{K}^{-1} \cdot \mathrm{m}^{-2}\right.$ measured using optical-transient grating method $)^{18-22}$, on STO substrates $\left(1 \times 10^{7}-2 \times 10^{7} \mathrm{~W} \cdot \mathrm{K}^{-1} \cdot \mathrm{m}^{-2}\right.$ measured using optical-transient grating method and thermoelectric method $)^{22,23}$, and semiconductor YBCO on MgO substrates $\left(5 \times 10^{6} \mathrm{~W} \cdot \mathrm{K}^{-1} \cdot \mathrm{m}^{-2}\right)^{24}$. For manganese oxides, some values have been reported for $\mathrm{La}_{0.7}\left(\mathrm{~Pb}_{0.7} \mathrm{Sr}_{0.3}\right)_{0.3} \mathrm{MnO}_{3}$ thin films on $\mathrm{STO}$ and $\mathrm{LaAlO}_{3}$ substrates $\left(10^{7} \mathrm{~W} \cdot \mathrm{K}^{-1} \cdot \mathrm{m}^{-2}\right.$ measured using pulsed microwave method $)^{25}$, and $\mathrm{La}_{0.65} \mathrm{Ca}_{0.35} \mathrm{MnO}_{3}$ on STO substrate $\left(\geq 10^{6} \mathrm{~W} \cdot \mathrm{K}^{-1} \cdot \mathrm{m}^{-2}\right.$ measured using pulsed microwave method $)^{26}$.

\section{Heat diffusion into substrate}

Thermal models describing the optical responsivity of high critical temperature superconducting film-on-substrate bolometers at different modulation frequency ranges can be found in literature ${ }^{5,6,23,27-31}$. Fardmanesh et al. ${ }^{27,28}$ proposed a one-dimensional (1D) thermal model for HTS thin film bolometers on thick substrates. They modeled the substrate as a cylinder and used the heat diffusion equation. This model was validated for large superconducting patterned areas compared with the substrate thickness at low and midrange modulation frequencies $(1 \mathrm{~Hz}-10 \mathrm{kHz})$. Fardmanesh et al. ${ }^{29}$ presented a 2D analytical model that better describes the results especially at high frequencies compared to the previous 1Dmodel. Gaugue et al. ${ }^{30}$ have also developed a 2D analytic model and a 3D numerical model, with and without consideration of the thermal boundary conductance between film and substrate. They showed that the 2D model can be used to predict the optical responsivity of an illuminated pixel, and the 3D model to evaluate inter-pixel crosstalk taking into account the thermal interface. More recently, and based on the last work, Jagtap et al. ${ }^{24}$ implemented a 3D thermal model taking into account the film/substrate interface and film thickness. Grossmann 
et $a l .{ }^{31}$ have proposed a $2 \mathrm{D}$ analysis for microbolometer arrays, which allows the analysis of thermal crosstalk and estimates the effects of finite substrate thickness. Most of the above cited models concern detection areas larger than substrate thickness. They do not strictly apply to our case where active detection areas are ranging from $50 \mu \mathrm{m} \times 50 \mu \mathrm{m}$ to $200 \mu \mathrm{m} \times 200 \mu \mathrm{m}$ on substrate thickness of $1 \mathrm{~mm}$.

We have modeled the contact between the film and the substrate as an hemisphere of radius a, as shown in figure 2 and previously proposed in Ref. 5 and Ref. 6. In this model the heat flux is radial into the substrate. The contact area is represented by a hemisphere of surface $2 \pi \mathrm{a}^{2}$, which is set equal to the surface of the thin film bolometer $\mathrm{A}=\mathrm{L}^{2}$, in case of a square of side L. The heat transfer equations in solids can be found in ${ }^{32}$. From the integration of the temperature gradient over the contact area between film and substrate $\left(A=L^{2}=2 \pi \mathrm{a}^{2}\right)$, the thermal conductance of the substrate $\mathrm{G}_{\mathrm{S}}$ can be written as ${ }^{5,6}$ :

$$
G_{S}(f)=L \times \kappa_{S} \times \sqrt{2 \pi} \times \sqrt{\left(1+\sqrt{\frac{f}{2 f_{L}}}\right)^{2}+\left(\frac{f}{2 f_{L}}\right)}
$$

where $\mathrm{f}$ is the incident power modulation frequency (in $\mathrm{Hz}), \kappa_{\mathrm{S}}$ is the substrate thermal conductivity (in $\mathrm{W} \cdot \mathrm{m}^{-1} \cdot \mathrm{K}^{-1}$ ), $\mathrm{f}_{\mathrm{L}}=\mathrm{D} / \mathrm{L}^{2}$ is the frequency at which the thermal diffusion length $\mathrm{L}_{\mathrm{D}}=\sqrt{\mathrm{D} /(\pi \mathrm{f})}$ (in $\mathrm{m}$ ) becomes equal to $\mathrm{a} \times \sqrt{2} . \mathrm{L}_{\mathrm{D}}$ gives the characteristic penetration depth of temperature variation into the substrate $e^{5,6,27-32}$. D is called the thermal diffusivity of the material, and has units of $\mathrm{m}^{2} \cdot \mathrm{s}^{-1}$. It measures the ability of a material to conduct thermal energy relative to its ability to store thermal energy and is defined as $D=\kappa /\left(c_{p} \times \rho_{v}\right)$, where $c_{p}$ is the specific heat capacity at constant pressure expressed in $\mathrm{J} \cdot \mathrm{kg}^{-1} \cdot \mathrm{K}^{-1}, \rho_{\mathrm{v}}$ is the mass density expressed in $\mathrm{kg} \cdot \mathrm{m}^{-3}$, and $\kappa$ is the thermal conductivity expressed in $\mathrm{W} \cdot \mathrm{m}^{-1} \cdot \mathrm{K}^{-1}$.

Depending on the modulation frequency f compared to $\mathrm{f}_{\mathrm{L}}$, two asymptotic behaviors can be distinguished as reported in table I. At low frequency, so called hereafter static regime, (where $L_{D} \gg>\times \sqrt{2}$, which means that the heat flows deep into the substrate), the thermal conductance of the substrate writes:

$$
\mathrm{G}_{\mathrm{S}}\left(\mathrm{f} \ll \mathrm{f}_{\mathrm{L}}\right)=\mathrm{G}_{\mathrm{S}}(0)=\mathrm{L} \times \kappa_{\mathrm{S}} \times \sqrt{2 \pi}
$$

In the static regime, $\mathrm{G}_{\mathrm{S}}$ is therefore independent of the modulation frequency, varies linearly with sample size $\mathrm{L}$ and the thermal conductivity of the substrate material $\kappa_{\mathrm{S}}$. At high frequency, so called dynamic regime, (where $\mathrm{L}_{\mathrm{D}}<<\mathrm{a} \times \sqrt{2}$, which means that the heat does not 
flow deep into the substrate and that the thermal boundary conductance may play an important role in the total thermal conductance as will be seen later), the thermal conductance of the substrate writes:

$$
\mathrm{G}_{\mathrm{S}}\left(\mathrm{f}>>\mathrm{f}_{\mathrm{L}}\right)=\mathrm{L} \times \kappa_{\mathrm{S}} \times \sqrt{2 \pi} \times \sqrt{\frac{\mathrm{f}}{\mathrm{f}_{\mathrm{L}}}}
$$

In the dynamic regime, $\mathrm{G}_{\mathrm{S}}$ therefore depends on frequency as $\mathrm{f}^{1 / 2}$.

In order to fully characterize the electro-thermal properties of the thin-film-on-substrate bolometer, one also has to evaluate its thermal capacitance. For a thin film bolometer element with area $\mathrm{A}=\mathrm{L}^{2}$ and thickness $\mathrm{t}_{\mathrm{F}}$, the film thermal capacitance can be neglected because of the very small volume involved and the total thermal capacitance can be estimated by the substrate thermal capacitance $\mathrm{C}_{S}$. The latter depends on the heated volume, which depends on the modulation frequency and is therefore hard to define analytically. Rewriting equations (4) and (5) as $G_{S}\left(f<<f_{L}\right)=G_{S}(0)=\kappa_{S} \times L^{2} / a$ and $G_{S}\left(f>>f_{L}\right)=\kappa_{S} \times L^{2} /\left(L_{D} / \sqrt{2}\right)$, respectively, actually corresponds to the thermal conductance of a heated volume of square area $\mathrm{L}^{2}$ and thickness $a$ in the static regime $\left(f<<f_{L}\right)$ and of square area $L^{2}$ and thickness $L_{D} / \sqrt{2}$ in the dynamic regime $\left(f>>f_{L}\right)$. Two asymptotic expressions of $C_{S}$ depending on the modulation frequency compared to $\mathrm{f}_{\mathrm{L}}$ can then be written as reported in table $\mathrm{I}$.

\section{EXPERIMENTAL DETAILS}

\section{A. Sample description}

The $75 \mathrm{~nm}$ thick LSMO films were deposited by Pulsed Laser Deposition (PLD) at $720{ }^{\circ} \mathrm{C}$ in a $\mathrm{O}_{2}$ pressure of 0.35 mbar (i.e. $34.7 \mathrm{~Pa}$ ) on $1 \mathrm{~mm}$ thick STO (001) and on $\mathrm{MgO}$ (001) substrates. All LSMO films were (001) oriented as revealed by X-ray diffraction (figure 3 ). Inset of figure 3 shows the electrical resistivity versus temperature characteristics of the unpatterned LSMO films. In order to make low electrical resistive connections a $200 \mathrm{~nm}$ thick gold layer was deposited by ion-beam on the LSMO films. The latter were patterned by UV photolithography and argon ion etching to form meander-shaped strips that covers square areas of $50 \mu \mathrm{m} \times 50 \mu \mathrm{m}, 100 \mu \mathrm{m} \times 100 \mu \mathrm{m}$ and $200 \mu \mathrm{m} \times 200 \mu \mathrm{m}$ (see inset of figure 4). They can be composed of 5 or 7 lines, or only one, thus forming a square. Each meander includes two gold pads for supplying the bias current, and two gold pads carrying out the 
voltage measurements. The connections between the external circuitry and the patterned film with gold contact pads were finally made using aluminium wires by ultrasonic bonding.

\section{B. Measurement conditions}

The LSMO samples were glued using silver paste onto a copper plate equipped with a heating element (allowing to heat in the $300-380 \mathrm{~K}$ range) and placed in a vacuum chamber equipped with an optical window. The chamber was evacuated by a secondary pump, and no cooling system was used. A temperature controller was used to maintain a temperature stability of $\pm 15 \mathrm{mK}$ during measurements at a fixed temperature. The LSMO meanders were current biased in a four probe configuration using a quasi-ideal dc current source, which exhibits quasi infinite output impedance and negligible noise contribution. ${ }^{33} \mathrm{~A}$ low-noise voltage amplifier with gain of 220 was used to measure the voltage of the LSMO samples.

Many methods to measure the thermal conductance of thin films, which can significantly deviate from its bulk form ${ }_{2}^{34}$ have been reported in literature. Among them, we can cite the $3 \omega$ method $^{35,36}$, the non-contact photothermal method ${ }^{37}$, and the electrothermal method $^{38}$. The thermal conductance can be experimentally seen as the inverse of the ratio of the temperature elevation $\Delta \mathrm{T}(\mathrm{f})$ of the bolometer that receives the power $\Delta \mathrm{P}(\mathrm{f})$. In our experiments, we used two types of incoming power. In the static regime, we used Joule heating to induce a temperature increase in the meander-shaped strips (electrothermal method). In the dynamic regime $(1 \mathrm{~Hz}-100 \mathrm{kHz}$ range), we used a modulated laser diode $(635 \mathrm{~nm}, 5 \mathrm{~mW})$ to heat the meanders, and we recorded the optical responsivity $\mathfrak{R}_{\mathrm{V}}(\mathrm{f})$ versus modulation frequency (photothermal method). Measured and modelled (using calculated G(f)) optical responsivity $\mathfrak{R}_{\mathrm{V}}(\mathrm{f})$ versus modulation frequency will be compared.

The electrothermal technique was found to be more accurate to determine the value of $\mathrm{G}(0)$ and will be described below. Voltage versus current V(I) and electrical resistance versus temperature $R(T)$ characteristics were used. The $V(I)$ was measured, using the precision parameter analyzer HP4156B, by applying a sweep varying bias current (I) in the devices (using the two current pads: I+, I-) and by measuring the voltage (V) across it (using the two voltage pads: $\mathrm{V}+, \mathrm{V}-)$. The $\mathrm{R}(\mathrm{I})$ characteristics can be easily calculated from $\mathrm{V}(\mathrm{I})$ by dividing $\mathrm{V}$ by $\mathrm{I}$. The $\mathrm{R}(\mathrm{T})$ characteristics have to be measured independently. By fitting the $\mathrm{R}(\mathrm{T})$ data in the vicinity of the temperature of the experiment $\mathrm{T}_{0}$ using a linear expression, we can deduce the temperature of the bolometer $T(R)$ as function of its electrical resistance $R$. The temperature of the bolometer $\mathrm{T}$ can finally be expressed as function of the dissipated electrical 
power $\mathrm{P}_{\mathrm{J}}=\mathrm{V} \times \mathrm{I}$ in the bolometer electrical resistance due to Joule effect to obtain $\mathrm{T}\left(\mathrm{P}_{\mathrm{J}}\right)$ characteristics from the $\mathrm{R}(\mathrm{I})$ characteristics, by substituting $\mathrm{R}$ to $\mathrm{T}$, and $\mathrm{I}$ to $\mathrm{P}_{\mathrm{J}}$, respectively. The slope at the origin (at $\mathrm{T}_{0}$ ) of the $\mathrm{P}_{\mathrm{J}}(\mathrm{T})$ characteristics directly gives $\mathrm{G}(0)$, the total thermal conductance of the LSMO film-on-substrate bolometers in the static regime (i.e. $\mathrm{f}<<\mathrm{f}_{\mathrm{L}}$ ).

\section{MEASUREMENTS AND ANALYSIS}

\section{A. Thermal properties of the substrate}

Table II summarizes the thermal properties of the different substrate materials used in our experiments, together with those of the LSMO film and the copper used as sample holder. The thermal conductivity of STO is five times smaller than that of $\mathrm{MgO}$, but they have close volumetric thermal capacity $c_{\mathrm{p}} \times \rho_{\mathrm{v}}$. The values for D mentioned in table II have been calculated using the reported $\kappa, c_{p}$ and $\rho_{v}$ values.

\section{B. Simplified model}

Considering our actual experimental conditions, equation (2) describing the total thermal conductance of the thin-film-on-substrate bolometers can be simplified. The substrate thickness is $1 \mathrm{~mm}$, which is always higher than a $\left(\mathrm{a}=\mathrm{L} \times(2 \pi)^{-1 / 2}\right)$. It means that the heat flow from the film surface does not exceed the substrate thickness, thus $\left(\mathrm{A}^{\prime} \cdot \mathrm{g}_{\mathrm{ST}}\right)^{-1}$ being negligible. Finally, considering the LSMO film thickness $t_{F}=75 \mathrm{~nm}$, we have a>>t for all the investigated bolometer areas. Consequently, the total thermal conductance of our LSMO thinfilm-on-substrate bolometers of surface $\mathrm{A}$ is given by :

$$
\frac{1}{G(f)}=\frac{1}{A \times g_{F S}}+\frac{1}{G_{S}(f)}
$$

where $G_{S}(f)$ is given by equation (3). It is recalled here that in this model the lateral heat flow is assumed to be negligible in comparison to the perpendicular one.

The overall expression of $\mathrm{G}(\mathrm{f})$ can finally be written, using equations (3) and (6) as:

$$
G(f)=\frac{L^{2} \times \kappa_{S} \times \sqrt{2 \pi} \times \sqrt{\left(1+\sqrt{\frac{f}{2 f_{L}}}\right)^{2}+\left(\frac{f}{2 f_{L}}\right)}}{L+\frac{\kappa_{S}}{g_{F S}} \times \sqrt{2 \pi} \times \sqrt{\left(1+\sqrt{\frac{f}{2 f_{L}}}\right)^{2}+\left(\frac{f}{2 f_{L}}\right)}}
$$


Equation (7) and equation (1) show that the optical responsivity of thin-film-onsubstrate bolometers will be mainly influenced by the thermal properties of the substrate material $\left(\kappa_{\mathrm{S}}\right.$ and $c_{\mathrm{pS}} \times \rho_{\mathrm{VS}}$ through $\mathrm{f}_{\mathrm{L}}$ ), and by the thermal boundary conductance at the film/substrate interface $\left(\mathrm{g}_{\mathrm{FS}}\right)$.

\section{Measurement of the thermal boundary conductance at the film/substrate interface}

Both calculated values of $\mathrm{G}_{\mathrm{S}}(0)$, i.e. the thermal conductance of the substrate in the static regime using equation (4), and measured $\mathrm{G}(0)$ values will be used to estimate $\mathrm{g}_{\mathrm{FS}} \mathrm{G}(0)$ values were measured as described in section III. Typical electrical power versus temperature characteristics resulting from voltage versus current $\mathrm{V}(\mathrm{I})$ and electrical resistance versus temperature $\mathrm{R}(\mathrm{T})$ characteristics are shown in figure 4 for all the studied LSMO patterned geometries on STO (001). The measured $\mathrm{G}(0)$ values at $330 \mathrm{~K}$ are presented in table III and figure 5 for both STO and $\mathrm{MgO}$ substrates. Fitting of measured $\mathrm{G}(0)$ values versus $\mathrm{L}$ characteristics using equation (8)

$$
\mathrm{G}(0)=\frac{\mathrm{L}^{2}}{\frac{1}{\mathrm{~g}_{\mathrm{FS}}}+\frac{\mathrm{L}}{\sqrt{2 \pi} \times \kappa_{\mathrm{S}}}}
$$

and $\kappa_{\mathrm{S}}$ values of table II gives thermal boundary conductance at the film/substrate interface $\mathrm{g}_{\mathrm{FS}}$ of $0.28 \pm 0.08 \times 10^{6} \mathrm{~W} \cdot \mathrm{K}^{-1} \cdot \mathrm{m}^{-2}$ for LSMO / STO $(001)$ and $5.80 \pm 2.98 \times 10^{6} \mathrm{~W} \cdot \mathrm{K}^{-1} \cdot \mathrm{m}^{-2}$ for LSMO / MgO (001). Values of $\mathrm{g}_{\mathrm{FS}}$ for LSMO / MgO (001) are more than one order of magnitude higher than for on STO (001), and showed higher dispersion. When L is reduced, $\mathrm{G}(0)$ is more dependent on the thermal boundary conductance of the film/substrate interface, whereas at large $\mathrm{L}$ values, the substrate thermal conductivity is more influent. At these large sizes, the penetration length becomes higher and the role of the substrate material dominates the total thermal conductance.

\section{Frequency behaviour}

The good agreement between calculated and measured static total thermal conductance was demonstrated in section D. We will now consider the dynamic behaviour of the thermal conductance and of the thermal capacitance in order to express the frequency response of the bolometer responsivity using equations (3) and (7), asymptotic expressions of $\mathrm{C}_{\mathrm{S}}$ given in table I, numerical values of the material thermal properties given in table II, and measured values of 
the thermal conductance $\mathrm{g}_{\mathrm{FS}}$. The frontier between the two asymptotic regions is obtained at $\mathrm{f}=\mathrm{f}_{\mathrm{L}}$ for the thermal conductance and for the thermal capacitance.

The normalized modulus of the measured optical responsivity versus modulation frequency of the laser diode has been compared to the normalized calculated elevation of temperature $\Delta \mathrm{T}(\mathrm{f})$ produced by the absorption of a power $\Delta \mathrm{P}(\mathrm{f})$, which writes as :

$$
\left.\frac{\Delta \mathrm{T}(\mathrm{f})}{\Delta \mathrm{P}(\mathrm{f})}\right|_{\text {Normalized at } 1 \mathrm{~Hz}}=\left(\frac{\mathrm{G}(0)}{\mathrm{G}(\mathrm{f}) \sqrt{1+\left(2 \pi \mathrm{f} \frac{\mathrm{C}_{\mathrm{S}}(\mathrm{f})}{\mathrm{G}(\mathrm{f})}\right)^{2}}}\right)
$$

using equation (1), G(f) given in equation (7) and $\mathrm{C}_{S}(\mathrm{f})$ given in table I. Measurements and calculations using equation (9) are compared in figures 6-a) and 6-b) for all sample sizes and both substrate materials. The frequency response of the measured optical responsivity and of the calculated elevation of temperature both show a low-pass behavior. Measurements show a plateau region at low frequencies, a $\mathrm{f}^{-1}$ dependence at high frequencies $(>10 \mathrm{kHz})$, and a $\mathrm{f}^{-1 / 2}$ dependence at the intermediate frequencies. The proposed calculations does not reproduce the $\mathrm{f}^{-1}$ dependence observed at high frequencies. We can also observe that the discrepancy between calculations and measurements is higher for the smaller sample areas for both LSMO/STO and LSMO/MgO samples, which very probably originates from the 1D nature of the model. Indeed the lateral diffusion of heat in the LSMO film and in the substrate is not taken into account. It can explain why the measured cut-off frequencies at $-3 \mathrm{~dB}$ reported in Table IV are always smaller (with a higher difference again for the smaller areas) than the calculated ones, in which the heated volume is underestimated. However as reported in table IV, the calculations reproduce satisfactorily the measured cut-off frequencies, taking into account the fact that calculations were made using equation (9) without any fitting using thermal parameter values of substrate materials found in literature. Simple calculations based on the basic first order model also show that the cut-off frequencies $\mathrm{f}_{0}=\mathrm{G}(0) /\left(2 \pi \mathrm{C}_{S}(0)\right)$ are about 2-3 times lower than $\mathrm{f}_{\mathrm{L}}$ values. Therefore only the model taking into account the dependence of both $\mathrm{G}$ and $\mathrm{C}$ with frequency can be used to calculate the cut-off frequency of the studied LSMO thin film on STO or MgO substrates. Compared to suspended structures where the thermal conductance can be lowered by 3 orders of magnitude [49], the LSMO thin-film-on-substrate bolometers offer the possibility of realizing relatively fast bolometers while keeping high enough sensitivity, which is currently under evaluation. 


\section{CONCLUSION}

A one dimensional thermal modeling of the thermal conductance of LSMO thin film on substrate bolometers has been presented. Calculations in both the static and the dynamic regimes were compared to measurements. In the static regime, the thermal conductance was measured using electrical heating whereas in the dynamic regime, the frequency response of the thermal conductance was measured using optical heating from a laser diode. The model allows estimating thermal boundary conductance values at the interface between film and substrate of $0.28 \pm 0.08 \times 10^{6} \mathrm{~W} \cdot \mathrm{K}^{-1} \cdot \mathrm{m}^{-2}$ for LSMO / STO $(001)$ and $5.80 \pm 2.98 \times 10^{6} \mathrm{~W} \cdot \mathrm{K}^{-1} \cdot \mathrm{m}^{-}$

2 for LSMO / MgO (001). Some discrepancy between calculations and measurements in the dynamic mode was observed, which was higher for the smaller sample areas, and probably originates from the 1D nature of the model. Finally, the overall good agreement between measurements and model both in the static and dynamic modes allows predicting the frequency response of the responsivity of LSMO thin film bolometers on different substrate materials, knowing their thermal properties. The model can be used to define optimized dimensions for bolometer presenting either higher responsivity or higher cut-off frequency depending on the targeted application.

\section{ACKNOWLEDGMENTS :}

The authors wish to acknowledge S. Lebargy and J. Gasnier for their technical support. 


\section{REFERENCES}

1 H. Budzier and G. Gerlach, Thermal Infrared Sensors, John Wiley \& Sons Inc. (2011).

2 P.W. Kruse, L.D. McGlauchlin and R.B. McQuistan, Elements of Infrared Technology, Wiley, New York (1962).

3 A. Rogalski, Infrared detectors: 2nd ed., CRC Press, (2011).

4 P. L. Richards, J. Appl. Phys., 76, 1 (1994).

5 T - L. Hwang, S. E. Schwarz, and D. B. Rutledge, Appl. Phys. Lett., 34, 773 (1979).

6 Q. Hu and P. L. Richards, Appl. Phys. Lett. 55, 2444 (1989).

7 A. Urushibara, Y. Moritomo, T. Arima, A. Asamitsu, G. Kido and Y. Tokura, Phys. Rev. B, 51, 14103 (1995).

8 A. Goyal, M. Rajeswari, R. Shreekala, S. E. Lofland, S. M. Bhagat, T. Boettcher, C. Kwon, and T. Venkatesan, Appl. Phys. Lett. 71, 2535 (1997).

9 L. Méchin, J.-M. Routoure, B. Guillet, F. Yang, S. Flament, and D. Robbes, J. Appl. Phys, 87, 204103 (2005).

10 F. Yang, L. Méchin, J.-M. Routoure, B. Guillet, and R. A. Chakalov, J. Appl. Phys, 99, 024903 (2006).

11 L. Méchin, J.-M. Routoure, S. Mercone, F. Yang, S. Flament, and R. A. Chakalov, J. Appl. Phys. 103, 083709 (2008).

12 L. Méchin, S. Wu, B. Guillet, P. Perna, C. Fur, S. Lebargy, C. Adamo, D.G. Schlom, J.M. Routoure, J. Phys. D: Appl. Phys. - Fast Track Communication 46202001 (2013).

13 J. H. Lienhard, A heat transfer text book, 3rd edition, Phlogiston Press-Cambridge, 62, (2008).

14 A. Bozbey, Investigation, modelling, and applications feasibility of thermal crosstalk in high Tc transition edge bolometer arrays, Univ. Bilkent, PhD Thesis (2008)

15 F. Kreith, R. M. Manglik, M. S. Bohn, Principles of Heat Transfer, $7^{\text {th }}$ edition, Cengage Learning, 10 (2011).

16 T. L. Bergman, A. S. Lavine, F. P. Incropera, D. P. Dewitt, $7^{\text {th }}$ Edition, John Wiley \& Sons, 68, (2011).

17 M. Nahum, S. Verghese, P. L. Richards, and K. Char, Appl. Phys. Lett., 59, 2034 (1991).

18 R. J. Stevens, L. V. Zhigilei, P. M. Norris, J. Heat Transfer, 50, 3977 (2007)

19 M. Kelkar, P. E. Phelan and B. Gu, Int. J. Heat Mass Transfer., 40, 2631 (1997). 
C. D. Marshall, I. M. Fishman and M. D. Fayer, Phys. Rev. B, 43, 2696 (1991).

C. D. Marshall, I. M. Fishman, R. C. Dorfman, C. B. Eom and M. D. Fayer, Phys. Rev. B, 45, 10009 (1992).

C. D. Marshall, A. Tokmakoff, I. M. Fishman, C. B. Eom, Julia M. Phillips and M. D. Fayer, J. Appl. Phys., 73, 850 (1993).

S. Zeuner, H. Lengfellner, and W. Prettl, Phys. Rev. B, 51, 11903 (1994).

V. S. Jagtap, A. Scheuring, M. Longhin, A. J. Kreisler, and A. F. Dégardin, IEEE T. Appl. Supercon., 19, (3) 287 (2009).

Y. V. Medvedev, Y. M. Nikolaenko, A. M. Grishin, and S. I. Khartsev, Tech. Phys., 47, 114 (2002).

Y. M. Nikolaenko, Y. V. Medvedev, M. Ghafari, H. Hahn, and I. N. Chukanova, Tech. Phys. Let., 32, 904 (2006).

27 M. Fardmanesh, Applied Optics, 40, 1080 (2001).

28 M. Fardmanesh, A. Rothwarf, and K. J. Scoles, IEEE Trans. on Appl. Supercond., 5, 7 (1995).

M. Fardmanesh, A. Kokabi, A. Pourhashemi, A. Moftakharzadeh, S. Khorasani, M. Banzet, and J. Schubert, IEEE Trans. on Appl. Supercond., 19, 484 (2009).

A. Gaugue, P. Teste, J. Delerue, A. Gensbittel, A. De Luca, A. Kreisler, F. Voisin, G. Klisnick, and M. Redon, IEEE Trans. on Appl. Supercond., 11, 766 (2001).

E. N. Grossman , D. G. McDonald and J. E. Sauvageau, J. Appl. Phys., 68, 5409 (1990). London (1959).

33 J.-M. Routoure, D. Fadil, S. Flament, and L. Méchin, AIP Conference Proceedings, 922, 419 (2007).

34 F.R. Brotzen, Thin solid film, 207, 197 (1992).

35 D. G. Cahill, H. E. Fischer, T. Klitsner, E. T. Swartz, and R. O. Pohl, J. Vac. Sci. Technol. A, 7, 1259 (1989).

36 D. G. Cahill, Rev. Sci. Instrum. 61, 802 (1990).

37 O.W. Kading, H. Skurk, and K. E. Goodson, Appl. Phys. Lett., 65, 1629 (1994).

38 X. Zhang, H. Q. Xie, M. Fujii, H. Ago, K. Takahashi, T. Ikuta, H. Abe, and T. Shimizu, Appl. Phys. Lett., 86, 171912, (2005).

39 Y. Suemune, J. Phys. Soc. Jpn. 20174 (1965). 
40 A. Durán, F. Morales, L. Fuentes, and J. M. Siqueiros, J. Phys. Condens. Matter, 20, 085219 (2008).

41 A. M. Hofmeister, J. Appl. Phys., 107, 103532 (2010).

42 G. A. Slack, Phys. Rev., 126, 427 (1962).

43 Standard Thermodynamic Properties of Chemical Substances, CRC Press LLC, (2000).

44 D.R. Lide, ed., CRC Handbook of Chemistry and Physics, Internet version, 90th Edition, CRC Press, Boca Raton, FL., (2005).

45 R.W. Powell, C.Y. Ho and P.E. Liley, NSRDS-NBS8, National Bureau of Standards Reference Data Series, (1966).

46 L. M. Wang, J. -H. Lai, J. -L. Wu, Y. -K. Kuo, and C. L. Chang, J. Appl. Phys., 102, 023915 (2007).

47 Y. K. Kuo, R. T. Jiang, L. M. Wang, Chinese J. of Physics, 43, 745 (2005).

48 H.-Y. Lee, H.-J. Liu, C.-H. Hsu, and Y.-C. Liang, Thin Solid Films, 494, 325 (2006).

49 S. Liu, B. Guillet, A. Aryan, C. Adamo, C. Fur, J.-M. Routoure, F. Lemarié, D.G Schlom, L. Méchin, Microelectron. Eng. 111101 (2013). 
Table captions:

Table I: Expressions of the thermal conductance $G_{S}(f)$ and of the thermal capacitance $C_{S}(f)$ of the substrate as a function of the modulation frequency $f$ for a thin-film-on-substrate bolometer of surface $A=L^{2} . \kappa_{S}, c_{p S}$ and $\rho_{v S}$ are the thermal conductivity, the specific heat capacity at constant pressure and the mass density of the substrate material, respectively.

Table II: Thermal properties of the different materials used at $300 \mathrm{~K}$; $\kappa$ is thermal conductivity, $c_{p}$ is the specific heat capacity, $\rho_{v}$ is the mass density and D is the thermal diffusivity.

Table III: Measured G(0) values for all the studied LSMO patterned geometries on both STO (001) and $\mathrm{MgO}(001)$ substrates at $330 \mathrm{~K} . \mathrm{G}(0)$ values are shown together with their standard deviations ( $95.4 \%$ confidence interval).

Table IV: Calculated $\mathrm{f}_{0}=\mathrm{G}(0) /\left(2 \pi \mathrm{C}_{\mathrm{S}}(0)\right)$, $\mathrm{f}_{\mathrm{L}}$, calculated and measured cut-off frequency $\mathrm{f}_{\mathrm{C}}$ at $3 \mathrm{~dB}$ for all sample sizes and both substrate materials. 
Figure captions:

Figure 1: Equivalent electrical circuit using electro-thermal analogy used to describe our thinfilm-on-substrate bolometers.

Figure 2: (a) Schematic representation of the film/substrate contact area in three dimensions showing the hemisphere of surface $2 \pi \mathrm{a}^{2}$, which is set equal to the surface of the film $A=L^{2}$; (b) a two dimensional cross section, where $t_{F}$ is the film thickness and $t_{S}$ is the substrate thickness.

Figure 3: X-ray diffraction patterns in the $\theta-2 \theta$ configuration of the LSMO films on STO (001) and $\mathrm{MgO}$ (001) substrates. Inset shows the electrical resistivity versus temperature characteristics of the unpatterned LSMO films.

Figure 4: Measured electrical power versus temperature characteristics for all the studied LSMO patterned geometries on STO (001) substrates at $330 \mathrm{~K}$.

Figure 5: Measured and calculated using equation (9) total static thermal conductance $G(0)$ of the LSMO film-on-substrate bolometers.

Figure 6: Measured and calculated (using Eq. 9) responsivity normalized at $1 \mathrm{~Hz}$ at $330 \mathrm{~K}$ for LSMO film on (a) STO, (b) MgO, and (c) dependence of the measured and calculated cut-off frequencies (from graphs a and b) versus sample size L. 
Table I: Expressions of the thermal conductance $G_{S}(f)$ and of the thermal capacitance $C_{S}(f)$ of the substrate as a function of the modulation frequency $\mathrm{f}$ for a thin-film-on-substrate bolometer of surface $\mathrm{A}=\mathrm{L}^{2} . \kappa_{\mathrm{S}}, \mathrm{c}_{\mathrm{pS}}$ and $\rho_{\mathrm{vS}}$ are the thermal conductivity, the specific heat capacity at constant pressure and the mass density of the substrate material, respectively.

\begin{tabular}{|c|c|c|}
\hline & $\mathrm{f} \ll<\mathrm{f}_{\mathrm{L}}$ & $\mathrm{f} \gg>\mathrm{f}_{\mathrm{L}}$ \\
\hline Heated volume & $\mathrm{L}^{2} \times \mathrm{a}$ & $\mathrm{L}^{2} \times \mathrm{L}_{\mathrm{D}} / \sqrt{2}$ \\
\hline $\begin{array}{l}\text { Substrate thermal } \\
\text { conductance } \mathrm{G}_{\mathrm{S}}(\mathrm{f})\end{array}$ & $\mathrm{L} \times \kappa_{\mathrm{S}} \times \sqrt{2 \pi}$ & $\mathrm{L} \times \kappa_{\mathrm{S}} \times \sqrt{2 \pi} \times \sqrt{\frac{\mathrm{f}}{\mathrm{f}_{\mathrm{L}}}}$ \\
\hline $\begin{array}{l}\text { Substrate thermal } \\
\text { capacitance } \mathrm{C}_{\mathrm{S}}(\mathrm{f})\end{array}$ & $\frac{\mathrm{L}^{3} \times \mathrm{c}_{\mathrm{pS}} \times \rho_{\mathrm{vS}}}{\sqrt{2 \pi}}$ & $\frac{\mathrm{L}^{3} \times \mathrm{c}_{\mathrm{pS}} \times \rho_{\mathrm{vS}}}{\sqrt{2 \pi}} \sqrt{\frac{\mathrm{f}_{\mathrm{L}}}{\mathrm{f}}}$ \\
\hline
\end{tabular}

Table II: Thermal properties of the different materials used at $300 \mathrm{~K} ; \kappa$ is thermal conductivity, $c_{p}$ is the specific heat capacity, $\rho_{v}$ is the mass density and $D$ is the thermal diffusivity.

\begin{tabular}{|l|c|c|c|c|}
\hline & $\begin{array}{c}\boldsymbol{\kappa} \\
\left(\mathbf{W} \cdot \mathbf{m}^{-\mathbf{1}} \cdot \mathbf{K}^{-\mathbf{1}}\right)\end{array}$ & $\begin{array}{c}\mathbf{c}_{\mathbf{p}} \\
\left(\mathbf{J} \cdot \mathbf{k g}^{\mathbf{- 1}} \cdot \mathbf{K}^{-\mathbf{1}}\right)\end{array}$ & $\begin{array}{c}\boldsymbol{\rho}_{\mathbf{v}} \\
\left(\mathbf{k g} \cdot \mathbf{m}^{\mathbf{- 3}}\right)\end{array}$ & $\begin{array}{c}\mathbf{D} \\
\left(\mathbf{1 0}^{-\mathbf{6}} \mathbf{~}^{\mathbf{2}} \cdot \mathbf{s}^{\mathbf{- 1}}\right)\end{array}$ \\
\hline STO & $12^{39}$ & $\begin{array}{r}544^{40} \text { Erreur } \\
\text { Source du } \\
\text { renvoi } \\
\text { introuvable. }\end{array}$ & $5170^{41}$ & 4.3 \\
\hline MgO & $51^{42}$ & $923^{43}$ & $3600^{44}$ & 15.4 \\
\hline Cu & $398^{45}$ & $381^{43}$ & $8960^{44}$ & 117 \\
\hline LSMO & $2.46^{46}$ & $568^{46,47}$ & $6600^{48}$ & 0.7 \\
\hline
\end{tabular}

Table III: Measured G(0) values for all the studied LSMO patterned geometries on both STO (001) and $\mathrm{MgO}(001)$ substrates at $330 \mathrm{~K} . \mathrm{G}(0)$ values are shown together with their standard deviations ( $95.4 \%$ confidence interval).

\begin{tabular}{|c|c|c|}
\hline \multirow{2}{*}{$\begin{array}{c}\text { Sample size } \\
\mathrm{L}(\mu \mathrm{m})\end{array}$} & \multicolumn{2}{|c|}{$\mathrm{G}(0)\left(\times 10^{-3} \mathrm{~W} \cdot \mathrm{K}^{-1}\right)$} \\
\cline { 2 - 3 } & LSMO & LSMO \\
& $/ \mathrm{STO}(001)$ & $\mathrm{MgO}(001)$ \\
\hline 50 & $0.85 \pm 0.02$ & $5.91 \pm 0.76$ \\
\hline
\end{tabular}




\begin{tabular}{|l|c|c|}
\hline 100 & $1.86 \pm 0.05$ & $10.09 \pm 0.84$ \\
\hline 200 & $3.21 \pm 0.18$ & $20.77 \pm 1.60$ \\
\hline
\end{tabular}

Table IV: Calculated $\mathrm{f}_{0}=\mathrm{G}(0) /\left(2 \pi \mathrm{C}_{\mathrm{S}}(0)\right), \mathrm{f}_{\mathrm{L}}$, calculated and measured cut-off frequency $\mathrm{f}_{\mathrm{C}}$ at $3 \mathrm{~dB}$ for all sample sizes and both substrate materials.

\begin{tabular}{|c|c|c|c|c|c|c|c|c|}
\hline & \multicolumn{4}{|c|}{ STO } & \multicolumn{4}{c|}{$\mathrm{MgO}$} \\
\hline $\begin{array}{c}\text { Sample size } \\
(\mu \mathrm{m})\end{array}$ & $\mathrm{f}_{0}(\mathrm{~Hz})$ & $\mathrm{f}_{\mathrm{L}}(\mathrm{Hz})$ & $\mathrm{f}_{\mathrm{C}}(\mathrm{Hz})$ & $\mathrm{f}_{\mathrm{C}}(\mathrm{Hz})$ & $\mathrm{f}_{0}(\mathrm{~Hz})$ & $\mathrm{f}_{\mathrm{L}}(\mathrm{Hz})$ & $\mathrm{f}_{\mathrm{C}}(\mathrm{Hz})$ & $\mathrm{f}_{\mathrm{C}}(\mathrm{Hz})$ \\
$($ calc. $)$ & $($ calc. $)$ & $($ calc. $)$ & $($ meas. $)$ & $($ calc. $)$ & $($ calc. $)$ & $($ calc. $)$ & $($ meas. $)$ \\
\hline 50 & 542 & 1720 & 487 & 254 & 4262 & 6160 & 2405 & 1029 \\
\hline 100 & 206 & 430 & 161 & 94 & 1258 & 1540 & 554 & 415 \\
\hline 200 & 69 & 108 & 49 & 48 & 345 & 385 & 135 & 139 \\
\hline
\end{tabular}




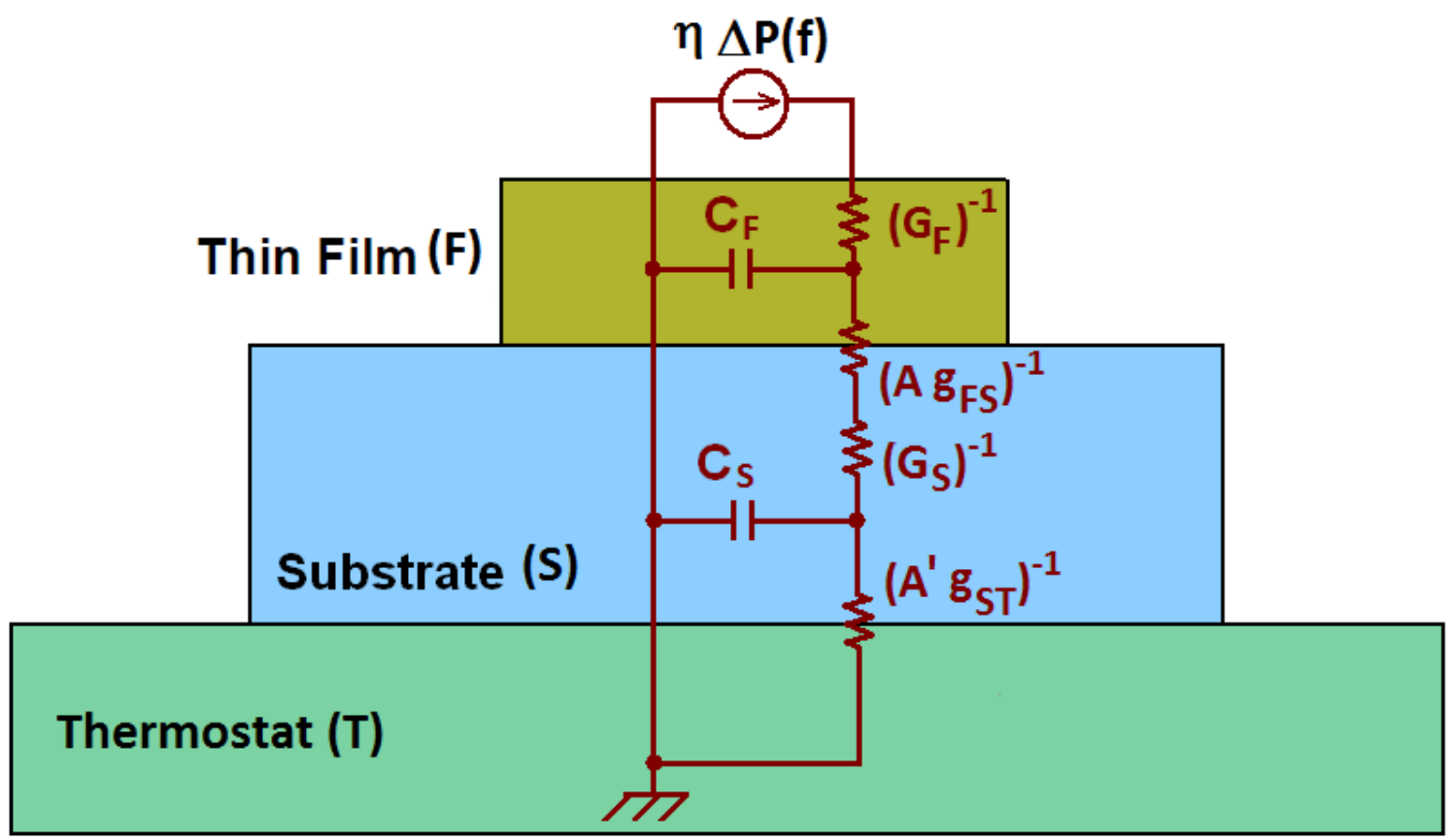

Figure 1: Equivalent electrical circuit using electro-thermal analogy used to describe our thinfilm-on-substrate bolometers. 

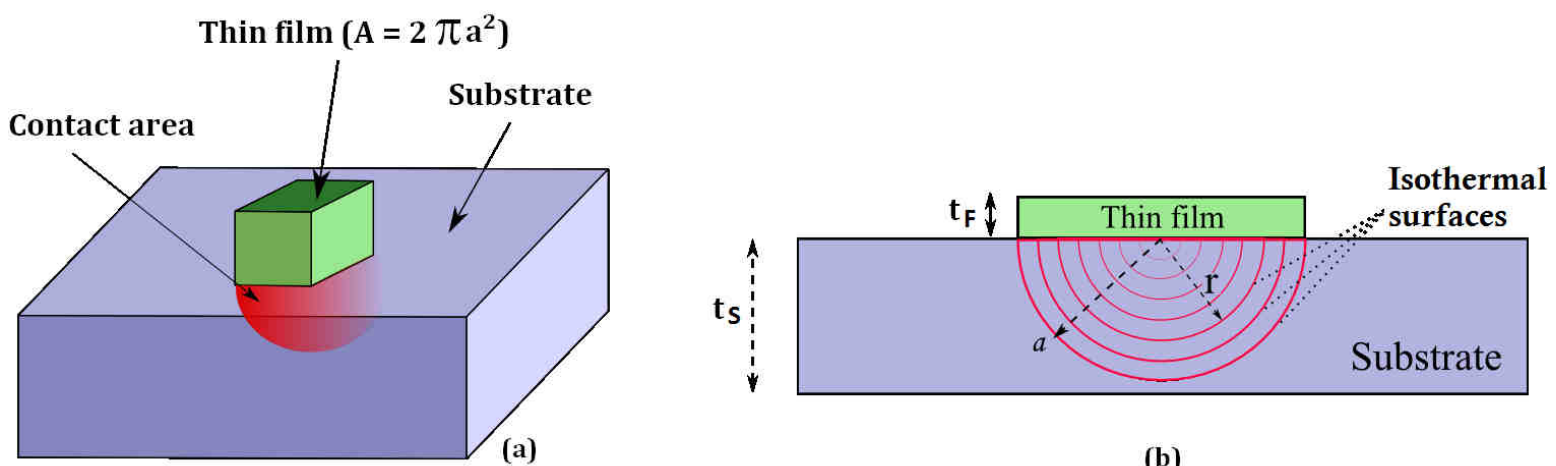

(b)

Figure 2: (a) Schematic representation of the film/substrate contact area in three dimensions showing the hemisphere of surface $2 \pi \mathrm{a}^{2}$, which is set equal to the surface of the film $A=\mathrm{L}^{2}$; (b) a two dimensional cross section, where $t_{\mathrm{F}}$ is the film thickness and $t_{\mathrm{S}}$ is the substrate thickness. 


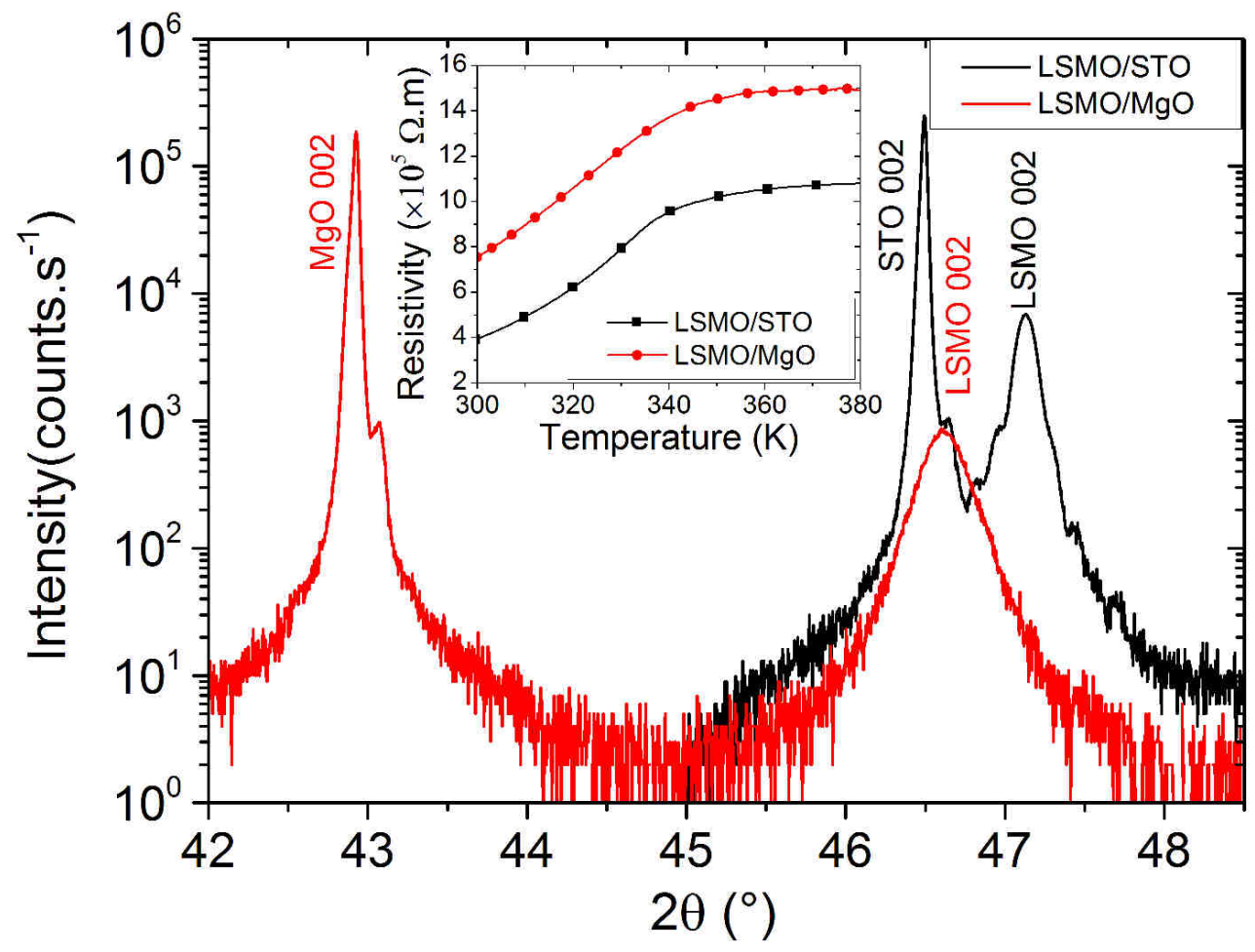

Figure 3: X-ray diffraction patterns in the $\theta-2 \theta$ configuration of the LSMO films on STO (001) and $\mathrm{MgO}$ (001) substrates. Inset shows the electrical resistivity versus temperature characteristics of the unpatterned LSMO films. 


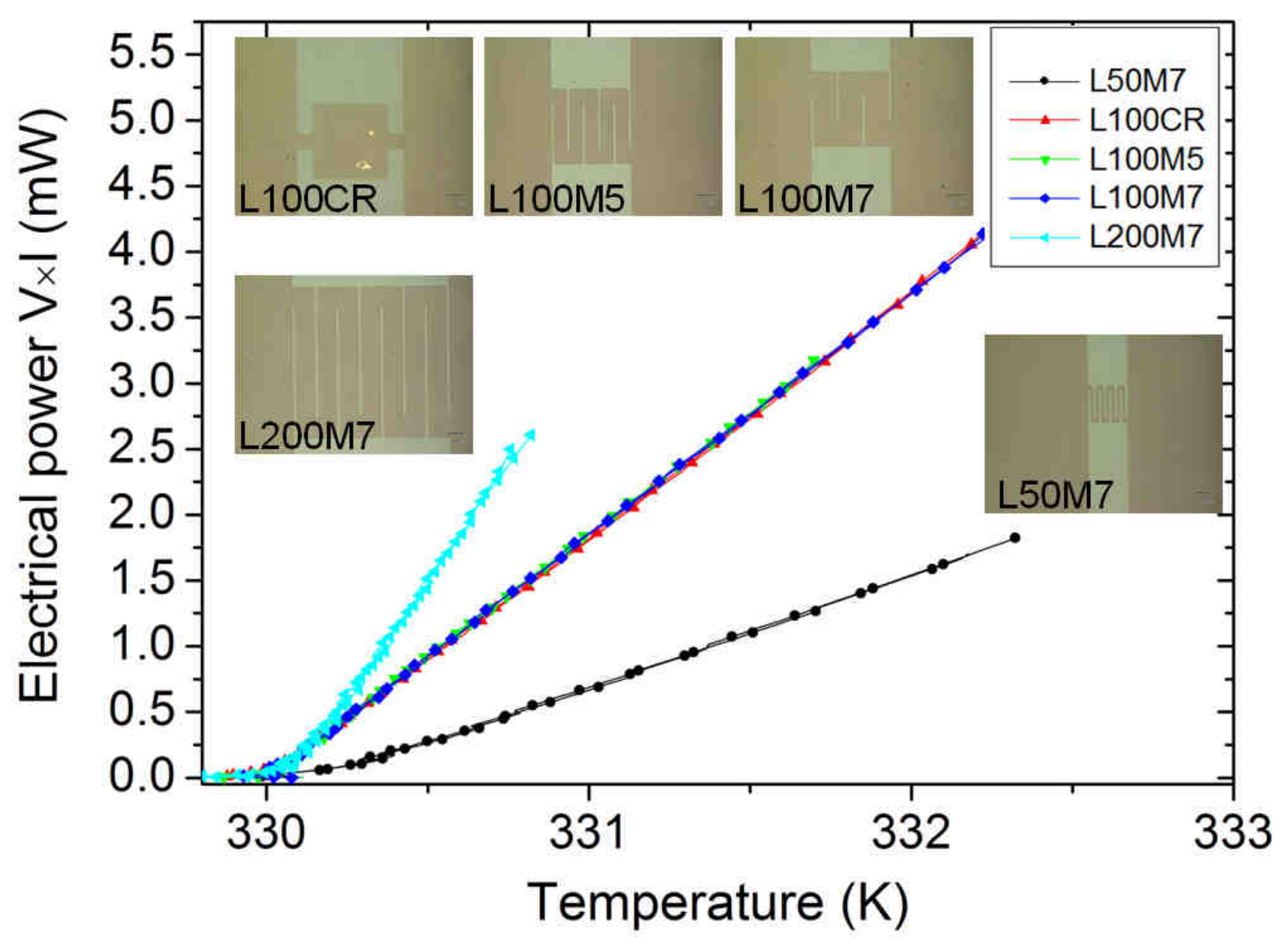

Figure 4: Measured electrical power versus temperature characteristics for all the studied LSMO patterned geometries on STO (001) substrates at $330 \mathrm{~K}$. 


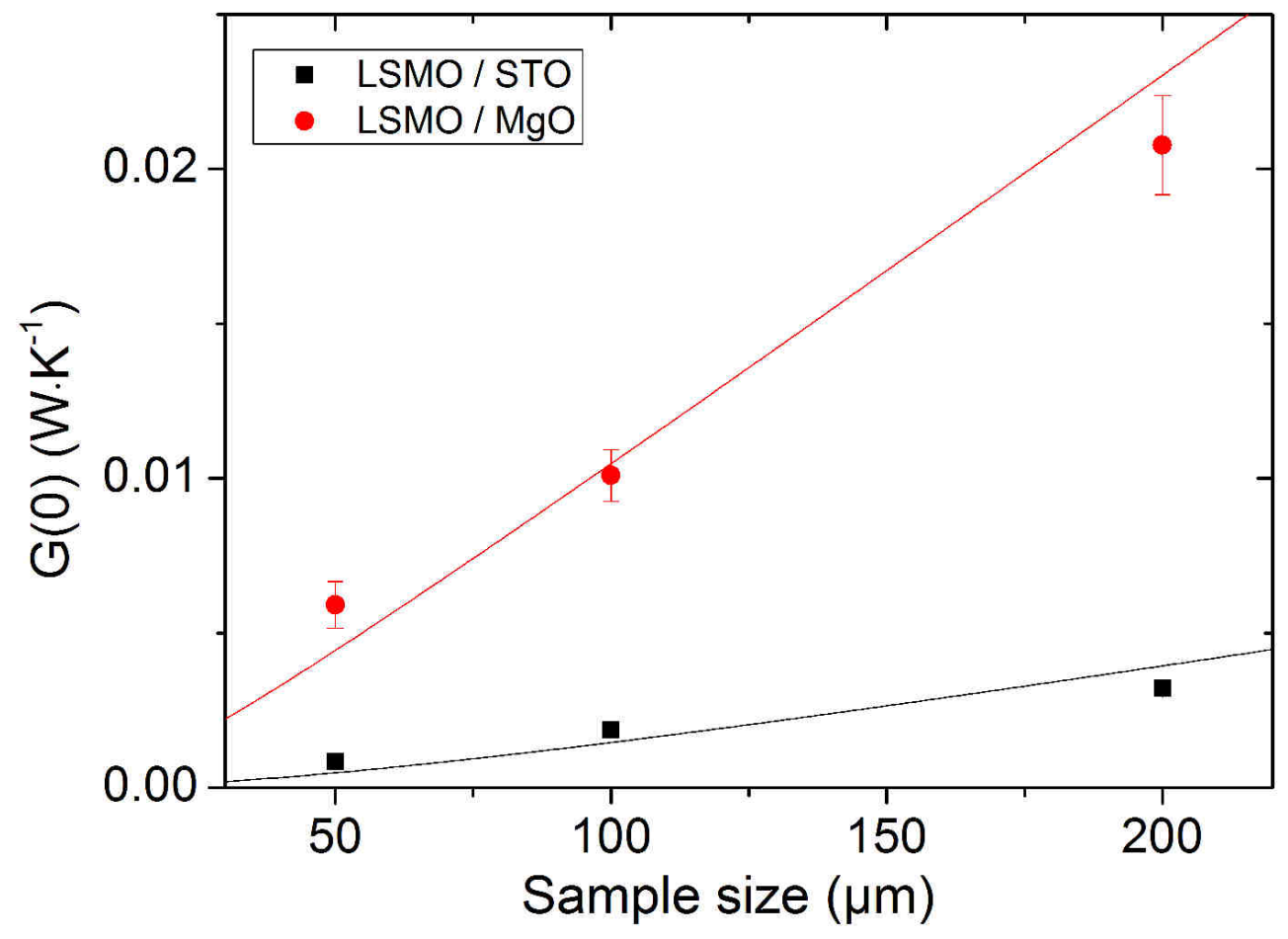

Figure 5: Measured and calculated using equation (9) total static thermal conductance $\mathrm{G}(0)$ of the LSMO film-on-substrate bolometers. 

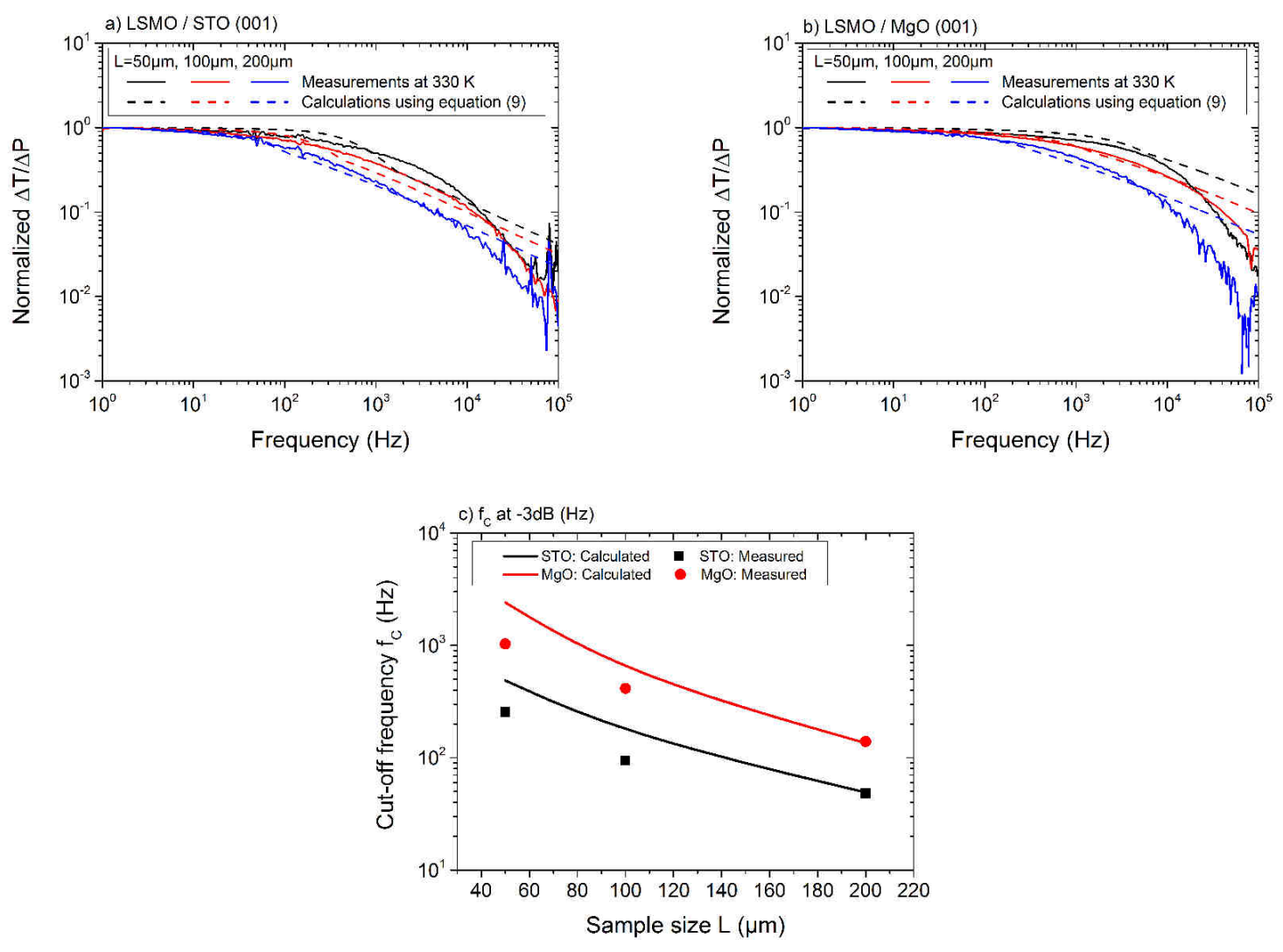

Figure 6: Measured and calculated (using Eq. 9) responsivity normalized at $1 \mathrm{~Hz}$ at $330 \mathrm{~K}$ for LSMO film on (a) STO, (b) MgO, and (c) dependence of the measured and calculated cut-off frequencies (from graphs a and $b$ ) versus sample size $\mathrm{L}$. 